\title{
Protective role of appendicectomy on onset and severity of ulcerative colitis and Crohn's disease
}

\author{
G L Radford-Smith, J E Edwards, D M Purdie, N Pandeya, M Watson, N G Martin, \\ A Green, B Newman, T H J Florin
}

See end of article for authors' affiliations

Correspondence to: Dr G L Radford-Smith Department of Gastroenterology, Level 9A, Ned Hanlon Building, Royal Brisbane Hospital, PO Herston, Brisbane, Qld, 4029, Australia; Graham_Radford-Smith@ health.qld.gov.au

Accepted for publication 26 July 2002

\begin{abstract}
Background and aims: Recent studies on appendicectomy rates in ulcerative colitis and Crohn's disease have generally not addressed the effect of appendicectomy on disease characteristics. The aims of this study were to compare appendicectomy rates in Australian inflammatory bowel disease patients and matched controls, and to evaluate the effect of prior appendicectomy on disease characteristics. Methods: Patients were ascertained from the Brisbane Inflammatory Bowel Disease database. Controls matched for age and sex were randomly selected from the Australian Twin Registry. Disease characteristics included age at diagnosis, disease site, need for immunosuppression, and intestinal resection. Results: The study confirmed the significant negative association between appendicectomy and ulcerative colitis (odds ratio (OR) 0.23 , 95\% confidence interval (CI) $0.14-0.38 ; p<0.0001$ ) and found a similar result for Crohn's disease once the bias of appendicectomy at diagnosis was addressed (OR $0.34,95 \% \mathrm{Cl} 0.23-0.51 ; \mathrm{p}<0.0001$ ). Prior appendicectomy delayed age of presentation for both diseases and was statistically significant for Crohn's disease ( $p=0.02)$. In ulcerative colitis, patients with prior appendicectomy had clinically milder disease with reduced requirement for immunosuppression (OR $0.15,95 \% \mathrm{Cl} 0.02-1.15 ; \mathrm{p}=0.04)$ and proctocolectomy $(\mathrm{p}=0.02)$.

Conclusions: Compared with patients without prior appendicectomy, appendicectomy before diagnosis delays disease onset in ulcerative colitis and Crohn's disease and gives rise to a milder disease phenotype in ulcerative colitis.
\end{abstract}

C rohn's disease (CD) and ulcerative colitis (UC) represent the most common forms of idiopathic inflammatory bowel disease (IBD), with a prevalence of $0.2-0.5 \%$ within Caucasian populations. ${ }^{1}$ Both diseases are associated with episodes of acute or chronic inflammation affecting either the large bowel alone (UC) or both the small and large bowel (CD). ${ }^{2}$ This intestinal inflammation is characterised by the presence of activated $\mathrm{T}$ and $\mathrm{B}$ lymphocytes and macrophages, and is thought to be an inappropriate response to local commensal bacteria. ${ }^{3}$ Both genetic and environmental factors play a role in determining this response and after extensive research the first IBD susceptibility gene, Nod2, has been identified on chromosome $16 .{ }^{45}$ Cigarette smoking remains the only environmental agent that has been confirmed as an independent risk factor. ${ }^{6}$ Smoking is positively associated with the development of $\mathrm{CD}$ and can make the disease worse. In contrast, there is a significant protective effect of smoking on $\mathrm{UC}$ and nicotine patches have been used effectively to treat mild UC.

More recently, there has been increasing interest in the role of the appendix on the development of IBD. There have now been 18 independent studies investigating this relationship of which 15 showed a highly significant negative association between appendicectomy and UC. ${ }^{8-25}$ Patients with CD were similarly assessed in 10 of 18 studies, and although eight showed a positive association in only one study was this statistically significant. ${ }^{8}$ At least two studies, one of which included both incident and prevalent cases, indicated that a significantly larger proportion of appendicectomies in patients with $\mathrm{CD}$ had been performed close to the time of diagnosis of the disease. ${ }^{1622}$ Two hypotheses have been generated from these studies which are not mutually exclusive. Firstly, patients who have an appendicectomy differ from those who develop UC in terms of genetic or environmental risk factors; and secondly, early appendicectomy modifies the intestinal immune response to protect against the development of UC. There is some support for the first hypothesis with a recent population based analysis indicating that only appendicectomy for inflammatory disorders (appendicitis or mesenteric adenitis) protects against the development of UC. ${ }^{21}$ This study also confirmed the relevance of age at appendicectomy, with those individuals who had undergone surgery before 20 years gaining protection, as initially suggested by Duggan and colleagues. ${ }^{17}$ However, there was no clear association between domestic hygiene, assessed by the prevalence of Helicobacter pylori serology and availability of hot running water, and the low rate of appendicectomy in UC patients. ${ }^{11}{ }^{17}$

Support for the second hypothesis comes from work on the $\mathrm{T}$ cell receptor $\alpha$ knockout murine model of colitis, where removal of the "caecal patch", considered to be equivalent to the human appendix, at 3-5 weeks of age suppressed the development of colitis. ${ }^{26}$ However, surgery at an older age ( $>6$ weeks) was less effective. Similarly, appendicectomy, but not splenectomy, in a DSS murine model of colitis significantly reduced the severity of disease compared with sham operated and unoperated control animals. ${ }^{27}$ In these animal models there was no evidence of appendicitis prior to surgery.

To extend the human studies, and specifically to investigate the clinical effects of early appendicectomy on patients with IBD, we have carried out a detailed analysis of appendicectomy in both UC and CD, using a large consecutive series of patients from two IBD centres and a large set of community based controls matched for age and sex, and who had previously reported on appendicectomy and smoking habits. ${ }^{28}$ We demonstrate a relationship between age at appendicectomy and IBD (for both UC and CD) and provide novel data on the role of appendicectomy in determining age of presentation of IBD and clinical severity of UC.

Abbreviations: $C D$, Crohn's disease; IBD, inflammatory bowel disease; UC, ulcerative colitis; OR, odds ratio. 


\section{METHODS \\ Patients}

Patients in this study were recruited by the Brisbane Inflammatory Bowel Disease Research Group which has an extensive clinical database that is based at the two major IBD referral centres within Brisbane. For analysis in this study, there were complete and informative data on 307 UC patients and 335 Crohn's patients. Those patients with a definite diagnosis of either UC or CD, based on standard clinical, radiological, and histological criteria as defined by Lennard-Jones, ${ }^{29}$ were consecutively entered onto a database between 1995 and 1999, after interview or after completing a detailed questionnaire. If the database entry or questionnaire was incomplete, the patient was contacted by telephone or seen in clinic to supply the missing information.

Specific questions relating to appendicectomy, indication for surgery, and date of surgery were incorporated into the database and questionnaire. The date of surgery in relation to the date of diagnosis of IBD was carefully assessed in order to investigate the precise relationship between appendicectomy and the risk of IBD. Therefore, appendicectomy performed after the diagnosis of IBD was disregarded for the purposes of this study. All histology reports available on patients who had undergone appendicectomy prior to a clear diagnosis of IBD were retrieved from archives or from patient records, and the slides reviewed to exclude the presence of either colitic- or CD-type changes, and to confirm the diagnosis of appendicitis or a histologically normal specimen. In all of these cases, the histopathologist was blinded to the clinical data pertaining to each of these patients.

Together with a history of all surgical episodes, the database recorded other phenotypic parameters including: date of diagnosis, site and distribution of disease, complications of IBD, disease activity (clinical, inflammatory indicators, pathological assessments), family history, radiological investigations, detailed smoking history, medications, and contact details, as well as appendicectomy, other surgery, and dates of surgery. The use of immunosuppressive therapy (defined as the use of azathioprine, 6-mercaptopurine, methotrexate, or mycophenolate for a minimum of 12 months' continuous treatment at standard recommended doses) to control disease activity, and all disease related surgical episodes were noted. Disease distribution for UC patients was simplified into two groups: those with disease limited to the left colon (up to the splenic flexure), including patients with ulcerative proctitis; and those with total or subtotal colitis (beyond the splenic flexure). Distribution was assessed macroscopically and microscopically at the time of diagnosis and at subsequent colonoscopies. The maximum extent recorded was used in the classification for this study, and the criterion for extent was based on histological (microscopic) distribution. CD patients were classified according to the distribution of their luminal disease apart from a small number of patients with pure perianal CD. The CD groups were as follows: ileal, ileocolonic, colonic, and pure perianal disease. These descriptors were based on colonoscopy, ileoscopy, histology, and small bowel contrast studies. Ethics approval was obtained from the respective hospitals' ethics committees and written, informed consent was obtained from all patients for entry of data onto the database.

\section{Controls}

Controls were randomly selected from a twin database that contains 3808 twin pairs from around Australia enrolled with the Australian Twin Registry. During 1980-1982, these twin pairs took part in a health survey by mailed questionnaire which included items on common operations, including appendicectomy, and lifestyle habits, including smoking. ${ }^{28}$ One twin from each pair was selected randomly as a control, and up to five of these controls were matched by sex and five year birth intervals to each IBD case.

\section{Statistical methods}

Smoking status was classified as never smoker, ex-smoker, or current smoker for patients and controls. Comparisons of categorical variables (such as smoking status and history of appendicectomy) between IBD cases and controls, and between cases with and without prior appendicectomy, were conducted using Pearson's $\chi^{2}$ statistic. Odds ratios (ORs), together with $95 \%$ confidence intervals (CIs), were calculated to estimate the relative risk of disease status associated with various exposures. Multiple logistic regression was used to remove the effect of potential confounding by age, sex, and smoking status on disease/exposure associations, with corresponding calculation of adjusted p values, ORs, and 95\% CIs. Comparisons of continuous approximately normally distributed variables such as age at diagnosis and time between appendicectomy and diagnosis were made using $t$ tests and analysis of variance (ANOVA). All analyses were performed using SAS for Windows Release 8.1 (Cary, North Carolina, USA, 2000).

\section{RESULTS}

\section{Characteristics of patients and controls}

Patients with left sided UC ( 173 or $56.5 \%$ ) outnumbered those with subtotal or total disease (133 or 43.5\%). Overall, 60 (19.6\%) UC patients required colectomy for control of severe or refractory disease and $72(23.5 \%)$ required immunosuppression for the same indications. Six patients $(2 \%)$ underwent colectomy for colorectal carcinoma or high grade dysplasia complicating their UC. There were more patients with ileal (37\%) and ileocolonic Crohn's disease (38\%) compared with pure colonic $(24 \%)$ and pure perianal disease $(0.9 \%)$. We found that $43 \%$ of CD patients required immunosuppression and $60 \%$ required at least one intestinal resection.

\section{Smoking and IBD}

For UC, current smoking appeared to be protective (OR 0.1, 95\% CI 0.1-0.2) but smoking prior to disease onset (ex-smokers) was positively related to disease (OR 2.7, 95\% CI 2.0-3.6) (table 1). The prevalence of never smokers was the same among UC cases (54\%) and controls (53\%). As expected, there was a positive association between smoking and CD, with current smokers being at a higher risk (OR 2.0, 95\% CI 1.5-2.6) than ex-smokers (OR 1.1, 95\% CI 0.7-1.6) (table 2). These results persisted after adjustment for age, sex, and appendicectomy.

\section{Appendicectomy rate and IBD}

Among UC patients, the overall rate of prior appendicectomy was $6.8 \%$ compared with $23.1 \%$ in controls, with an OR corrected for age, sex, and smoking of 0.23 (95\% CI 0.14-0.38; $\mathrm{p}<0.0001)$. This OR was even lower $(0.16,95 \%$ CI $0.08-0.32)$ among patients who had appendicectomy performed at or before the age of 20 years (table 1). Of all the CD patients, 65 had undergone appendicectomy at any time, of which 36 had appendicectomy prior to the diagnosis of $\mathrm{CD}$. Thus the prior appendicectomy rate for CD was $10.8 \%$ compared with $24.9 \%$ for age cohort controls, giving an adjusted OR of 0.34 (95\% CI $0.23-0.51 ; \mathrm{p}<0.0001)$. Once again, the OR was lower at 0.33 (95\% CI $0.2-0.53$ ) for appendicectomy performed at or prior to 20 years of age (table 2 ).

\section{Effect of prior appendicectomy on disease phenotype}

These data are consistent with a significant protective effect of appendicectomy on the incidence of both UC and CD. Therefore, we examined the relationship between appendicectomy and disease severity, which we postulated might be worse in IBD patients with their appendix in situ at the time of diagnosis (tables 3,4). Severity was assessed by (i) age at diagnosis, (ii) extent of disease, and (iii) need for immunosuppressive therapy and/or need for intestinal resection in order 
Table 1 Appendicectomy rates in ulcerative colitis patients and matched controls

\begin{tabular}{|c|c|c|c|c|c|c|c|}
\hline $\begin{array}{l}\text { Subject } \\
\text { characteristics }\end{array}$ & $\begin{array}{l}\text { Cases } \\
(n=307)\end{array}$ & $\begin{array}{l}\text { Controls } \\
(n=1016)\end{array}$ & $\begin{array}{l}\text { Crude } \\
\text { OR }\end{array}$ & e $95 \% \mathrm{Cl}$ & $\mathrm{p}$ Value & $\begin{array}{l}\text { Multivariate } \\
\text { analysis OR }\end{array}$ & $95 \% \mathrm{Cl}$ \\
\hline Mean (SEM) age (y) & $32.7(0.85)$ & $33.6(0.38)$ & & & 0.32 & & \\
\hline \multicolumn{8}{|c|}{ Sex } \\
\hline Female & $48.9 \%$ & $45.8 \%$ & & & 0.34 & & \\
\hline Male & $51.1 \%$ & $54.2 \%$ & & & & & \\
\hline \multicolumn{8}{|l|}{ Smoking } \\
\hline Never smoker & $54.4 \%$ & $52.6 \%$ & 1.00 & (referent) & & 1.00 & (referent) \\
\hline Current smoker & $3.3 \%$ & $32.1 \%$ & 0.10 & $0.05-0.19$ & & 0.10 & $0.05-0.19$ \\
\hline Ex-smoker & $\begin{array}{l}42.3 \% \\
(n=307)\end{array}$ & $\begin{array}{l}15.3 \% \\
(n=896)\end{array}$ & 2.71 & $2.03-3.64$ & $<0.0001$ & 3.29 & $2.38-4.56$ \\
\hline \multicolumn{8}{|l|}{ Appendicectomy } \\
\hline No & $93.2 \%$ & $76.9 \%$ & 1.00 & (referent) & & 1.00 & (referent) \\
\hline Yes & $\begin{array}{c}6.8 \% \\
(n=307)\end{array}$ & $\begin{array}{l}23.1 \% \\
(n=892)\end{array}$ & 0.23 & $0.15-0.39$ & $<0.0001$ & 0.23 & $0.14-0.38$ \\
\hline \multicolumn{8}{|c|}{ Age at appendicectomy } \\
\hline None & $93.2 \%$ & $77.1 \%$ & 1.00 & (referent) & & 1.00 & (referent) \\
\hline$\leqslant 20 y$ & $3.3 \%$ & $15.3 \%$ & 0.17 & $0.09-0.34$ & & 0.16 & $0.08-0.32$ \\
\hline$>20 y$ & $3.5 \%$ & $7.6 \%$ & 0.39 & $0.20-0.75$ & $<0.0001$ & 0.41 & $0.20-0.83$ \\
\hline
\end{tabular}

to control the disease (excluding colectomy or other intestinal resection for cancer or high grade dysplastic lesions).

Of 21 patients with UC who had an appendicectomy prior to their diagnosis, 20 had mild disease as defined by no requirement for immunosuppression or colectomy. These 20 patients were receiving no maintenance treatment $(n=3)$, an oral 5 -ASA agent alone $(n=14)$, or both oral and intermittent rectal 5-ASA $(n=3)$. Only one of $21(4.8 \%)$ patients has required ongoing immunosuppression compared with 71/286 (25\%) in the non-appendicectomy group $(\mathrm{p}=0.04)$. None of the 21 patients in the appendicectomy group underwent colectomy for clinically severe IBD compared with $60 / 281$ (21\%) patients in the rest of the UC cohort $(\mathrm{p}=0.02)$. When combining these two groups, only $1 / 21(4.8 \%)$ patients with a previous appendicectomy needed immunosuppression or colectomy compared with 106/281 (38\%) in the rest of the cohort (OR 0.09, $95 \%$ CI $0.04-0.81 ; \mathrm{p}=0.003)$. The one patient who has required ongoing immunosuppression for refractory UC in the appendicectomy group is Chinese, an ethnic group with a very low incidence of UC. Age at diagnosis tended to be later in those patients with prior appendicectomy (mean 38 years) compared with the rest of the cohort (mean 31 years) $(p=0.08)$. The UC cases with prior appendicectomy were more likely to have subtotal or total colitis (13/21 (62\%)) compared with $120 / 285(42 \%)$ in non-appendicectomy UC patients $(p=0.08)$.
Effect of prior appendicectomy on CD phenotype

Mean age at diagnosis in the 36 appendicectomy cases was greater (36 years) compared with the rest of the group (30 years) $(p=0.02)$. This difference remained significant after adjustment for sex, age, and smoking. Disease distribution in CD did not differ significantly between those 36 patients with a definite prior appendicectomy and the rest of the CD group $(n=299)$. Ileal cases included those with some inflammation in the adjacent caecum but no other colorectal disease. Similarly, disease behaviour, classified as stricturing, penetrating, or non-stricturing non-penetrating, ${ }^{30}$ was not influenced by prior appendicectomy $(\mathrm{p}=0.7)$. Mean duration between appendicectomy and diagnosis of CD did not correlate with disease site $(p=0.94)$. With respect to disease severity, use of immunosuppression was not significantly different between CD patients with appendicectomy $(14 / 36,39 \%)$ and those without appendicectomy $(130 / 299,43 \%)$. Rates of intestinal resection were also similar (177/299 or $59 \%$ in the nonappendicectomy group $v 23 / 36$ or $64 \%$ in the appendicectomy group).

\section{Histology of appendix in prior appendicectomy group}

Histology of the appendix was retrievable in 8/21 UC patients and in $8 / 36$ CD patients who had undergone a prior appendicectomy, as the majority of the patients had undergone surgery before 1980 and their records had been destroyed. Of

Table 2 Appendicectomy rates in Crohn's disease patients and matched controls

\begin{tabular}{|c|c|c|c|c|c|c|c|}
\hline Subject characteristics & $\begin{array}{l}\text { Cases } \\
(n=335)\end{array}$ & $\begin{array}{l}\text { Controls } \\
(n=941)\end{array}$ & $\begin{array}{l}\text { Crude } \\
\text { OR }\end{array}$ & $95 \% \mathrm{Cl}$ & $\mathrm{p}$ Value & $\begin{array}{l}\text { Multivariate } \\
\text { analysis OR }\end{array}$ & $95 \% \mathrm{Cl}$ \\
\hline Mean (SEM) age (y) & $30.3(0.79)$ & $31.1(0.39)$ & & & 0.33 & & \\
\hline \multicolumn{8}{|l|}{ Sex } \\
\hline Female & $67.2 \%$ & $66 \%$ & & & 0.70 & & \\
\hline Male & $32.8 \%$ & $34 \%$ & & & & & \\
\hline \multicolumn{8}{|l|}{ Smoking } \\
\hline Never smoker & $41.2 \%$ & $54.2 \%$ & 1.00 & (referent) & & 1.00 & (referent) \\
\hline Ex-smoker & $11.6 \%$ & $14.2 \%$ & 1.08 & $0.72-1.61$ & & 1.10 & $0.72-1.67$ \\
\hline Current smoker & $47.2 \%$ & $31.6 \%$ & 1.97 & $1.50-2.57$ & $<0.0001$ & 1.98 & $1.50-2.62$ \\
\hline Appendicectomy & $(n=335)$ & $(n=835)$ & & & & & \\
\hline No & $89.3 \%$ & $75.1 \%$ & 1.00 & (referent) & & 1.00 & (referent) \\
\hline Yes & $10.7 \%$ & $24.9 \%$ & 0.36 & $0.25-0.53$ & $<0.0001$ & 0.35 & $0.24-0.52$ \\
\hline Age at appendicectomy & $(n=335)$ & $(n=830)$ & & & & & \\
\hline None & 89.3 & $75.3 \%$ & 1.00 & (referent) & & 1.00 & (referent) \\
\hline$\leqslant 20 y$ & $6.5 \%$ & $16.5 \%$ & 0.34 & $0.21-0.54$ & & 0.33 & $0.21-0.53$ \\
\hline$>20 y$ & $4.2 \%$ & $8.2 \%$ & 0.43 & $0.24-0.78$ & $<0.0001$ & 0.41 & $0.22-0.75$ \\
\hline
\end{tabular}


Table 3 Effect of appendicectomy on ulcerative colitis characteristics ( $n=307$ )

\begin{tabular}{|c|c|c|c|c|c|c|c|}
\hline \multirow[b]{2}{*}{ Phenotype } & \multirow[b]{2}{*}{$\mathrm{n}$} & \multicolumn{4}{|c|}{ Appendicectomy } & \multirow[b]{2}{*}{ OR $(95 \% \mathrm{Cl})$} & \multirow[b]{2}{*}{$\mathrm{p}$ Value } \\
\hline & & \multicolumn{2}{|c|}{ Yes $(n=21)$} & \multicolumn{2}{|c|}{ No $(n=286)$} & & \\
\hline \multirow{2}{*}{\multicolumn{2}{|c|}{$\begin{array}{l}\text { Mean (SEM) age at diagnosis (y) } \\
\text { Colectomy* }\end{array}$}} & \multirow{2}{*}{\multicolumn{2}{|c|}{$37.8(2.8)$}} & \multicolumn{2}{|c|}{$31.3(1.0)$} & & 0.08 \\
\hline & & & & & & & \\
\hline No & 241 & 20 & (100\%) & 221 & $(78.6 \%)$ & & \\
\hline Yes & 60 & 0 & $(0 \%)$ & 60 & $(21.4 \%)$ & & 0.02 \\
\hline \multicolumn{8}{|l|}{ Immunosuppression } \\
\hline No & 235 & 20 & (95.2\%) & 215 & $(75.2 \%)$ & 1.00 (referent) & \\
\hline Yes & 72 & 1 & $(4.8 \%)$ & 71 & $(24.8 \%)$ & $0.15(0.02-1.15)$ & 0.04 \\
\hline \multicolumn{8}{|l|}{$\begin{array}{l}\text { Colectomy or } \\
\text { immunosuppression } \dagger\end{array}$} \\
\hline No & 195 & 20 & (95.2\%) & 175 & $(62.3 \%)$ & 1.00 (referent) & \\
\hline Yes & 107 & 1 & $(4.8 \%)$ & 106 & (37.7\%) & $0.09(0.01-0.66)$ & 0.003 \\
\hline \multicolumn{8}{|l|}{ Distribution } \\
\hline L\&P & 173 & 8 & $(38.1 \%)$ & 165 & $(57.9 \%)$ & 1.00 (referent) & \\
\hline S\&T & 133 & 13 & (61.9\%) & 120 & $(42.1 \%)$ & $2.23(0.9-5.56)$ & 0.08 \\
\hline \multicolumn{8}{|c|}{ Duration between appendicectomy and UC (y) } \\
\hline S\&T (mean (SEM)) & 13 & 15.5 & $(3.4)$ & - & & & \\
\hline L\&P (mean (SEM)) & 8 & 10.3 & $(2.7)$ & - & & & \\
\hline Overall (mean (SEM)) & 21 & 13.5 & $(2.4)$ & - & & & 0.30 \\
\hline
\end{tabular}

Table 4 Effect of appendicectomy on Crohn's disease characteristics ( $n=335$ )

\begin{tabular}{|c|c|c|c|c|c|c|c|}
\hline \multirow[b]{2}{*}{ Phenotype } & \multirow[b]{2}{*}{$\mathrm{n}$} & \multicolumn{4}{|c|}{ Appendicectomy } & \multirow[b]{2}{*}{ OR $(95 \% \mathrm{CI})$} & \multirow[b]{2}{*}{$\mathrm{p}$ Value } \\
\hline & & \multicolumn{2}{|c|}{ Yes $(n=36)$} & \multicolumn{2}{|c|}{ No $(n=299)$} & & \\
\hline \multirow{2}{*}{\multicolumn{2}{|c|}{$\begin{array}{l}\text { Mean (SEM) age at diagnosis (y) } \\
\text { Immunosuppression }\end{array}$}} & \multicolumn{2}{|c|}{$35.6(2.0)$} & \multicolumn{2}{|c|}{$29.6(0.9)$} & & $0.02 *$ \\
\hline & & & & & & & \\
\hline No & 191 & 22 & (61.1\%) & 169 & $(56.5 \%)$ & & \\
\hline Yes & 144 & 14 & (38.9\%) & 130 & $(43.5 \%)$ & $0.83(0.41-1.68)$ & 0.60 \\
\hline \multicolumn{8}{|l|}{ Bowel resection } \\
\hline No & 135 & 13 & (36.1\%) & 122 & $(40.8 \%)$ & & \\
\hline Yes & 200 & 23 & (63.9\%) & 177 & (59.2\%) & $1.22(0.59-2.50)$ & 0.59 \\
\hline \multicolumn{8}{|l|}{ Distribution } \\
\hline Ileocolonic & 128 & 8 & $(22.2 \%)$ & 120 & $(40.1 \%)$ & 1.9 (referent) & \\
\hline lleal & 123 & 18 & $(50 \%)$ & 105 & (35.1\%) & $2.4(1.0-5.9)$ & 0.14 \\
\hline Colonic & 81 & 9 & $(25.0 \%)$ & 72 & $(24.1 \%)$ & $1.9(0.70-5.2)$ & \\
\hline Perianal $†$ & 3 & 1 & $(2.8 \%)$ & 2 & $(0.7 \%)$ & - & \\
\hline \multicolumn{8}{|c|}{ Duration between appendicectomy and CD $(y) \ddagger$} \\
\hline lleal (mean (SEM)) & 18 & 15. & $(2.8)$ & - & & & \\
\hline Colonic (mean (SEM)) & 9 & 16. & $(4.4)$ & - & & & 0.94 \\
\hline lleocolonic (mean (SEM)) & 8 & 16. & $(2.7)$ & - & & & \\
\hline \multicolumn{8}{|c|}{ Age at appendicectomy among $C D$ patients $(y) \ddagger$} \\
\hline lleal (mean (SEM)) & 18 & 19. & $(2.4)$ & & & & \\
\hline Colonic (mean (SEM)) & 9 & 23. & $(3.4)$ & & & & \\
\hline Ileocolonic (mean (SEM)) & 8 & 16. & $(1.6)$ & & & & 0.28 \\
\hline
\end{tabular}

the 57 patients in the appendicectomy group, only five (three $\mathrm{CD}$, two UC) had undergone surgery within the two year period before their diagnosis. Histology was available on all of these patients and showed changes of typical mucosal appendicitis in all cases. Of the remaining 11 patients with available histological data, eight had definite mucosal appendicitis (four CD, four UC) and three had histologically normal appendices (one $\mathrm{CD}$, two $\mathrm{UC}$ ).

\section{DISCUSSION}

The present large and well controlled study confirms the significant negative association between appendicectomy and UC and also for the first time suggests the same association in CD if the confounding factor of surgery related to the disease itself is taken into account. In addition, the study indicates that prior appendicectomy may be associated with older age at diagnosis for both UC and CD, and with a clinically less severe course in patients with UC compared with patients with their appendix in situ. Finally, it also supports the importance of age at appendicectomy in UC, with early appendicectomy (before 20 years) conferring more protection than appendicectomy at an older age.

While our data in the UC population are comparable with those of the majority of other studies, with the statistical power in the current study being enhanced by large numbers of patients and controls, our CD data are not in agreement with these studies, which raises the possibility of a type I statistical error. Both the UC and CD groups were carefully collected, and the dates of previous surgery confirmed in all cases by direct patient interview and by referring to current or previous hospital records. We addressed the potential bias of appendicectomy in CD patients being directly related to the disease itself, and our values for UC patients $(6.8 \%)$ and CD patients $(10.8 \%)$ are both comparable with the respective 
incident values ( $6 \%$ for UC and 9\% for CD) given by Russel and colleagues. ${ }^{16}$ The prevalence of appendicectomy in our control population was high compared with control appendicectomy rates in other studies. This is because of the inclusion of appropriately age matched controls, and reflects the high appendicectomy rates that used to pertain in Australia. ${ }^{281}$ The controls in the present study were all drawn from a large community based twin population which permits great confidence in the interpretation of our data. The twins had volunteered to help in the collection of research data with respect to health and lifestyle, but were not accessed in relation to specific "hospital or health clinic seeking behaviour". In comparison, the majority of the other studies have used either small numbers of controls, hospital controls, or controls obtained from a general practitioner list. ${ }^{16}$

Data for smoking and UC are in agreement with previous studies. In particular, the increased risk of the disease in nonsmokers is the result of a large number of former smokers. ${ }^{32}{ }^{33}$ Data for smoking and CD suggest a stronger positive association between current smokers and the disease compared with ex-smokers in our cohort, which again is in agreement with the majority of previous studies. ${ }^{32}{ }^{33}$ Adjustment for smoking status did not weaken the negative associations between either UC or CD and previous appendicectomy.

Both the delay in disease presentation in IBD, which was evident for both UC and CD patients with prior appendicectomy, and the reduction in several disease severity parameters for patients with UC, are important novel observations. They are supported by the observations made in animal models of IBD. $^{26}{ }^{27}$ The results are also consistent with two previous studies that found that appendicectomy before age 20 years confers protection against $U^{1721}$ and with Naganuma et al who found that appendicectomy prior to a diagnosis of UC reduces relapse rate, as measured by the need for oral steroids. ${ }^{23}$

The lower OR values for UC compared with $\mathrm{CD}$ and the results of other studies indicate that appendicectomy is more protective for UC than CD. Previous work has suggested that UC pathogenesis may be dominated by a humoral or $\mathrm{B}$ lymphocyte immune response whereas CD is dominated by a strong $\mathrm{T}$ lymphocyte response. ${ }^{34-37}$ This, together with the above observations, suggests at least one hypothesis: the $\mathrm{B}$ lymphocyte component within the appendix may be necessary for seeding the immune system of the gut with IgA producing plasma cells. IgA (or IgM) produced by these cells has an important role in excluding bacteria. Aberrant immunoglobulin switching could result in pathological production of IgG which is not important for bacterial exclusion but by binding complement promotes a cellular immune response. ${ }^{38}$ If the appendix is removed early from a patient carrying the genetic susceptibility for developing UC (or CD), then this may be enough to either prevent or ameliorate the disease. On the other hand, although the disease may be milder, its extent may be increased because of diminished bacterial exclusion throughout the intestine. This hypothesis has indirect support from work on neonatal rabbits which shows diminished mucosal IgA, IgM, and IgG in the small bowel after early appendicectomy (levels were not reported for the colon). ${ }^{40}$

The alternative but not mutually exclusive hypothesis is that it is the inflammation of appendicitis (and/or mesenteric adenitis) that is important in conferring protection against UC. Our histological data are consistent with this hypothesis but do not exclude a role for appendicectomy per se. Andersson et al, who provided supportive evidence for appendicitis or mesenteric adenitis being necessary for protection against UC, argued that this might be due to dominance of a Thl cytokine profile in these patients compared with a Th2 cytokine profile associated with UC. ${ }^{21}$ However, appendicectomy was the sole end point for inclusion in their study and therefore removal of the appendix itself may also have been protective. Further- more, the Andersson study may have failed to capture many UC patients who had a prior appendicectomy. This is because only patients with UC that required hospital admission for their UC disease were included in the Andersson study. Yet in our study we demonstrated that it was these same patients who had appendicectomy that had mild disease and therefore may never have required hospital admission. Further support for this is the low appendicectomy rate $(0.9 \%)$ in our patients with refractory UC (requiring immunosuppression and/or colectomy) compared with the overall UC rate of $6.8 \%$. These patients all required hospital admission for UC.

In summary, our study strongly supports the negative age related association between prior appendicectomy and UC, and for the first time demonstrates a similar association for $\mathrm{CD}$. Comparative analysis clearly shows that prior appendicectomy is associated with a more benign phenotype in UC, and a delay in onset of IBD. These results are consistent with the hypothesis that the appendix contributes to the development and maintenance of the gut immune system, as suggested in animal models, but does not exclude an inverse relationship between appendicitis (and/or mesenteric adenitis) and IBD.

\section{ACKNOWLEDGEMENTS}

We gratefully acknowledge Pharmacia Australia Pty Ltd for supporting our database manager. Maintenance of a rigorous database has been essential for this work. We thank Dian Templeton, Sue Mason, and Valerie Logan for help with preparation of the manuscript.

\section{Authors' affiliations}

G L Radford-Smith, Department of Gastroenterology, Royal Brisbane Hospital, Brisbane, Australia 4029

J E Edwards, M Watson, Department of Gastroenterology, Royal Brisbane Hospital, Brisbane, Australia 4029, and University of

Queensland Department of Medicine, Mater Adult Hospital, South Brisbane, Australia 4101

D M Purdie, N Pandeya, N G Martin, A Green, Population Health Unit, Queensland Institute of Medical Research, Brisbane, Australia 4029

B Newman, Centre for Public Health Research, Queensland University of Technology, Brisbane, Australia 4059

T H J Florin , University of Queensland Department of Medicine, Mater Adult Hospital, South Brisbane, Australia 4101

\section{REFERENCES}

1 Montgomery SM, Morris DL, Thompson NP, et al. Prevalence of inflammatory bowel disease in British 26 year olds: national longitudinal birth cohort. BM 1998;316:1058-9.

2 Podolsky DK. Inflammatory bowel disease (1). N Engl J Med $1991 ; 325: 928-37$

3 Hanauer SB. Inflammatory bowel disease. N Engl J Med 1996;334:841-8

4 Hugot JP, Chamaillard M, Zouali $\mathrm{H}$, et al. Association of NOD2 leucine-rich repeat variants with susceptibility to Crohn's disease. Nature 2001:411:599-603.

5 Ogura $\mathrm{Y}$, Bonen DK, Inohara N, et al. A frameshift mutation in NOD2 associated with susceptibility to Crohn's disease. Nature 2001;411:603-6.

6 Tobin MV, Logan RF, Langman M, et al. Cigarette smoking and inflammatory bowel disease. Gastroenterology 1987:93:316-21.

7 Pullan RD, Rhodes J, Ganesh S, et al. Transdermal nicotine for active ulcerative colitis. N Engl J Med 1994;330:811-15.

8 Gilat T, Hacohen D, Lilos P, et al. Childhood factors in ulcerative colitis and Crohn's disease. An international cooperative study. Scand J Gastroenterol 1987:22:1009-24.

9 Wurzelmann JI, Lyles CM, Sandler RS. Childhood infections and the risk of inflammatory bowel disease. Dig Dis Sci 1994;39:555-60. 10 Rutgeerts P, D'Haens G, Hiele M, et al. Appendicectomy protects against ulcerative colitis. Gastroenterology 1994;106:1251-3.

11 Gent AE, Hellier MD, Grace RH, et al. Inflammatory bowel disease and domestic hygiene in infancy. Lancet 1994;343:766-7.

12 Smithson JE, Radford-Smith G, Jewell GP. Appendicectomy and tonsillectomy in patients with inflammatory bowel disease. $J$ Clin Gastroenterol 1995;21:283-6.

13 Breslin NP, McDonnell C, O'Morain C. Surgical and smoking history in inflammatory bowel disease: A case-control study. Inflamm Bowel Dis 1997; $3: 1-5$.

14 Parrello T, Pavia M, Angelillo IF, et al. Appendicectomy is an independent protective factor for ulcerative colitis: results of a multicentre case control study. The Italian Group for the Study of the Colon and Rectum (GISC). Ital J Gastroenterol Hepatol 1997;29:208-1 1 
15 Minocha A, Raczkowski CA. Role of appendicectomy and tonsillectomy in pathogenesis of ulcerative colitis. Dig Dis Sci 1997;42:1567-9.

16 Russel MG, Dorant E, Brummer RJ, et al. Appendicectomy and the risk of developing ulcerative colitis or Crohn's disease: results of a large case-control study. South Limburg Inflammatory Bowel Disease Study Group. Gastroenterology 1997;113:377-82.

17 Duggan AE, Usmani I, Neal KR, et al. Appendicectomy, childhood hygiene, Helicobacter pylori status, and risk of inflammatory bowel disease: a case control study (see comments). Gut 1998;43:494-8

18 Derby LE, Jick $\mathrm{H}$. Appendicectomy protects against ulcerative colitis. Epidemiology 1998;9:205-7.

19 Koutroubakis IE, Vlachonikolis IG, Kapsoritakis A, et al. Appendicectomy, tonsillectomy, and risk of inflammatory bowel disease: case-controlled study in Crete. Dis Colon Rectum 1999;42:225-30.

20 Dijkstra B, Bagshaw PF, Frizelle FA. Protective effect of appendicectomy on the development of ulcerative colitis: matched, case-control study. Dis Colon Rectum 1999;42:334-6.

21 Andersson RE, Olaison G, Tysk C, et al. Appendicectomy and protection against ulcerative colitis. N Engl J Med 2001;344:808-14.

22 Frisch M, Johansen C, Mellemkjaer L, et al. Appendicectomy and subsequent risk of inflammatory bowel diseases. Surgery $2001 ; 130: 36-43$.

23 Naganuma $M$, Lizuka $B$, Torii $A$, et al. Appendicectomy protects against the development of ulcerative colitis and reduces its recurrence: results of a multicenter case-controlled study in Japan. Am J Gastroenterol 2001;96:1123-6.

24 Reif S, Lavy A, Keter D, et al. Appendectomy is more frequent but not a risk factor in Crohn's disease while being more protective in ulcerative colitis: a comparison of surgical procedures in inflammatory bowel disease. Am J Gastroenterol 2001;96:829-32.

25 Lopez-Ramos D, Gabriel R, Cantero-Perona J, et al. Prevalence of appendectomy among ulcerative colitis patients and their relatives. Eur $J$ Gastroenterol Hepatol 2001;13:1231-3

26 Mizoguchi A, Mizoguchi E, Chiba C, et al. Role of appendix in the development of inflammatory bowel disease in TCR-alpha mutant mice. J Exp Med 1996;184:707-15.
27 Krieglstein CF, Cerwinka WH, Laroux FS, et al. Role of appendix and spleen in experimental colitis. J Surg Res 2001;101:166-75.

28 Duffy DL, Martin NG, Matthews JD. Appendicectomy in Australian twins. Am J Hum Genet 1990:47:590-92.

29 Lennard-Jones JE. Classification of inflammatory bowel disease. Scand J Gastroenterol Suppl 1989;170:2-6.

30 Gasche C, Scholmerich J, Brynskov J, et al. A simple classification of Crohn's disease: Report of the working party for the World Congresses of Gastroenterology, Vienna 1998. Inflamm Bowel Dis 2000;6:8-15.

31 Donnelly NJ, Semmens JB, Fletcher DR, et al. Appendicectomy in Western Australia: profile and trends, 1981-1997. Med J Aust 2001;175:15-18.

32 Lindberg $\mathbf{E}$, Tysk $C$, Andersson $\mathrm{K}$, et al. Smoking and inflammatory bowel disease. A case-control study. Gut 1988;29:352-57.

33 Calkins BM. A meta-analysis of the role of smoking in inflammatory bowel disease. Dig Dis Sci 1989;34:1841-54.

34 Pallone F, Monteleone G. Interleukin 12 and Th 1 responses in inflammatory bowel disease. Gut 1998;43:735-6.

35 Monteleone G, Biancone L, Marasco R, et al. Interleukin 12 is expressed and actively released by Crohn's disease intestinal lamina propria mononuclear cells. Gastroenterology 1997;112:1169-78.

36 Fuss IJ, Neurath M, Boirivant $M$, et al. Disparate CD4+ lamina propria (LP) lymphokine secretion profiles in inflammatory bowel disease. Crohn's disease LP cells manifest increased secretion of IFN-gamma, whereas ulcerative colitis LP cells manifest increased secretion of IL-5. J Immunol 1996;157:1261-70.

37 Snook J. Are the inflammatory bowel diseases autoimmune disorders? Gut 1990;31:961-3.

38 Scott BB, Goodall A, Stephenson P, et al. Rectal mucosal plasma cells in inflammatory bowel disease. Gut 1983;24:519-24.

39 MacDermott RP, Nahm MH. Expression of human immunoglobulin G subclasses in inflammatory bowel disease. Gastroenterology 1987;93:1 127-9.

40 Dasso JF, Howell MD. Neonatal appendicectomy impairs mucosal immunity in rabbits. Cell Immunol 1997;182:29-37. 